Article

\title{
Silkworm Pupae Function as Efficient Producers of Recombinant Glycoproteins with Stable-Isotope Labeling
}

\author{
Hirokazu Yagi ${ }^{1}{ }^{\oplus}$, Saeko Yanaka ${ }^{1,2}{ }^{\oplus}$, Rina Yogo ${ }^{1,2}{ }^{\circledR}$, Akari Ikeda $^{3}$, Masayoshi Onitsuka ${ }^{4}$, \\ Toshio Yamazaki ${ }^{5}$, Tatsuya Kato ${ }^{6}\left(\mathbb{D}\right.$, Enoch Y. Park ${ }^{6} \mathbb{(}$, Jun Yokoyama ${ }^{3}$ and Koichi Kato ${ }^{1,2, *(\mathbb{C})}$ \\ 1 Graduate School of Pharmaceutical Sciences, Nagoya City University, 3-1 Tanabe-dori, Mizuho-ku, \\ Nagoya 467-8603, Japan; hyagi@phar.nagoya-cu.ac.jp (H.Y.); saeko-yanaka@ims.ac.jp (S.Y.); \\ yogo@ims.ac.jp (R.Y.) \\ 2 Exploratory Research Center on Life and Living Systems (ExCELLS) and Institute for Molecular Science (IMS), \\ National Institutes of Natural Sciences, 5-1 Higashiyama, Myodaiji-cho, Okazaki 444-8787, Japan \\ 3 Taiyo Nippon Sanso Corporation, SI Innovation Center, 2008-2 Wada, Tama, Tokyo 206-0001, Japan; \\ ikedaa.qnm@tn-sanso.co.jp (A.I.); yokoyamaj.qrb@tn-sanso.co.jp (J.Y.) \\ 4 Graduate School of Technology, Industrial and Social Sciences, Tokushima University, \\ Minamijosanjima-cho 2-1, Tokushima 770-8513, Japan; onitsuka@tokushima-u.ac.jp \\ 5 SPring-8 Center RIKEN, 1-7-22 Suehiro-cho, Tsurumi-ku, Yokohama City, Kanagawa 230-0045, Japan; \\ toshio.yamazaki@riken.jp \\ 6 Laboratory of Biotechnology, Research Institute of Green Science and Technology, Shizuoka University, \\ 836 Ohya Suruga-ku, Shizuoka 422-8529, Japan; kato.tatsuya@shizuoka.ac.jp (T.K.); \\ park.enoch@shizuoka.ac.jp (E.Y.P.) \\ * Correspondence: kkatonmr@ims.ac.jp; Tel.: +81-564-59-5225
}

Received: 5 September 2020; Accepted: 23 October 2020; Published: 26 October 2020

\begin{abstract}
Baculovirus-infected silkworms are promising bioreactors for producing recombinant glycoproteins, including antibodies. Previously, we developed a method for isotope labeling of glycoproteins for nuclear magnetic resonance (NMR) studies using silkworm larvae reared on an artificial diet containing ${ }^{15} \mathrm{~N}$-labeled yeast crude protein extract. Here, we further develop this method by introducing a technique for the expression of isotope-labeled glycoproteins by silkworm pupae, which has several potential advantages relative to larvae-based techniques in terms of production yield, ease of handling, and storage. Here, we fed fifth instar larvae an artificial diet with an optimized composition containing [methyl ${ }^{13} \mathrm{C}$ ]methionine, leading to pupation. Nine-day-old pupae were then injected with recombinant Bombyx mori nucleopolyhedrovirus (BmNPV) bacmid for expression of recombinant human immunoglobulin $\mathrm{G}(\mathrm{IgG})$. From the whole-body homogenates of pupae, $0.35 \mathrm{mg} /$ pupa of IgG was harvested, which is a yield that is five times higher than can be obtained from larvae. Recombinant IgG, thus prepared, exhibited mainly three kinds of pauci-mannose-type oligosaccharides and had a ${ }^{13} \mathrm{C}$-enrichment ratio of approximately $80 \%$. This enabled selective observation of NMR signals originating from the methionyl methyl group of IgG, confirming its conformational integrity. These data demonstrate the utility of silkworm pupae as factories for producing recombinant glycoproteins with amino-acid-selective isotope labeling.
\end{abstract}

Keywords: silkworm pupa; isotope labeling; recombinant glycoprotein; artificial diet; immunoglobulin G 


\section{Introduction}

Recombinant proteins are widely used as research tools in every aspect of life science and, moreover, as pharmaceuticals, catalysts, and biomaterials in industrial applications. To date, a variety of options are available for producing recombinant proteins, especially in terms of choice of expression vehicles, which include bacteria, yeast, plants, insects, mammals, and even cell-free systems, according to purposes [1,2]. In making one's choice, production cost, yield, and ease of handling both in culture and during genetic manipulation are generally considered.

Recombinant proteins are often expressed with modifications, as exemplified by mutational modifications such as tagging, truncation, and/or amino-acid substitution and by post-translational modifications such as glycosylation. Isotope enrichment is also a useful modification, and is especially important for recombinant proteins subjected to structural analyses such as nuclear magnetic resonance (NMR) spectroscopy. At the laboratory level, Escherichia coli is one of the most widely used expression vehicles because of its innate advantages, i.e., fast growth, well-characterized genetics, cost-effectiveness, and high yield [3,4]. However, this conventional expression vehicle is not equipped with a glycosylation system. Therefore, eukaryotic vehicles are alternatively used for production of recombinant glycoproteins [1,2].

Several groups have developed stable-isotope labeling protocols to produce recombinant glycoproteins using eukaryotic expression systems [5-11]. Our group has reported protocols for the stable-isotope labeling of recombinant glycoproteins by transgenic tobacco, and silkworm larvae as well as mammalian cells, using immunoglobulin G (IgG) glycoproteins as models [12-15]. Recombinant IgG glycoproteins have been used as therapeutic antibodies and NMR spectroscopy has been considered as a useful tool for assessing their higher-order structural integrity [16].

In this context, a baculovirus-infected silkworm system serves as a highly efficient and cost-effective bioreactor for the production of heterologous glycoproteins including IgGs [17-19]. In this system, a Bombyx mori nucleopolyhedrovirus (BmNPV) bacmid containing the gene sequences of target proteins is injected into a silkworm larva. Several attempts have been made to improve production yield and to remodel functional glycosylation of B. mori-derived IgG glycoproteins. In our previous paper, we demonstrated that recombinant IgG with approximately $80 \%{ }^{15} \mathrm{~N}$ enrichment could be produced in maintaining structural integrity by silkworm larvae reared with an isotope-labeled artificial diet [14].

Here, we explore the possibility of exploiting silkworm pupae-instead of larvae-to produce isotope-labeled recombinant glycoproteins. Pupae possess potential advantages relative to larvae [17]. Pupae do not require feeding and do not move, and so are easier to maintain than larvae. Unlike larvae, pupae can be stored at a temperature of $4{ }^{\circ} \mathrm{C}$ for up to two weeks prior to bacmid injection, and can also produce higher yields of recombinant proteins than larvae.

In this study, we attempt to optimize a silkworm rearing condition so as to maximize production yield of recombinant IgG by the use of B.mori pupae. Since we have already achieved full ${ }^{15} \mathrm{~N}$ labeling [14], our trial in this study is designed to perform amino-acid selective ${ }^{13} \mathrm{C}$ labeling of IgG.

\section{Materials and Methods}

\subsection{Artificial Diets for Silkworm Rearing}

Artificial diets used for rearing silkworms consisted of the components described previously with modified compositions [20-22] (Table 1). Here, an artificial diet containing 40\% amino acid and $10 \%$ mulberry leaf powder is termed as A40M10. Similar notation will be used for other compositions of artificial diets. For amino-acid-selective isotope labeling, a protein mixture derived from the yeast strain, Candida utilis NBRC 0396, was replaced by an amino-acid mixture (Table 2) containing [methyl- $\left.{ }^{13} \mathrm{C}\right]$ methionine. 
Table 1. Compositions of artificial diets used to cultivate silkworm larvae.

\begin{tabular}{cccc}
\hline Substances & \multicolumn{3}{c}{ \% of Dry Diet } \\
\cline { 2 - 4 } Artificial diet & A40M10 & A30M10 & A20M20 \\
\hline Yeast protein & 40.0 & -4 & -4 \\
Amino acid mixture & -4 & 30.0 & 20.0 \\
Mulberrry leaf powder & 10.0 & 10.0 & 20.0 \\
Glucose & 12.0 & 15.0 & 15.0 \\
Soybean oil & 3.0 & 3.0 & 3.0 \\
Phytosterol & 0.3 & 0.3 & 0.3 \\
Ascorbic acid & 2.0 & 2.0 & 2.0 \\
Sorbic acid & 0.2 & 0.2 & 0.2 \\
Agar & 10.0 & 10.0 & 10.0 \\
Salt mixture & 4.2 & 4.2 & 4.2 \\
Vitamin B mixture & 0.4 & 0.4 & 0.4 \\
Cellulose powder & 17.9 & 24.9 & 24.9 \\
\hline (Total) $_{\text {Antiseptics }}^{3}$ & 100.0 & 100.0 & 100.0 \\
\hline Distilled water & Added & Added & Added \\
\hline mL/g diet & 3 mL/g diet & 3 mL/g diet \\
\hline
\end{tabular}

${ }^{1}$ See Reference [22]. ${ }^{2}$ See Reference [21]. ${ }^{3}$ Antiseptics consisted of chloramphenicol (0.015\% in diet) and propionic acid $\left(0.75 \%\right.$ in diet). ${ }^{4}$ Absent compound.

Table 2. Amino-acid compositions of the yeast protein/amino-acid mixture contained in the artificial diets.

\begin{tabular}{ccc}
\hline & Yeast Protein & Amino Acid Mixture \\
\hline Amino Acids & \multicolumn{3}{c}{ mol\% } \\
\hline Alanine & 9.30 & 10.75 \\
Arginine & 4.23 & 3.90 \\
Aspartic acid & 11.09 & 9.48 \\
Cysteine & & 2.82 \\
Glutamic acid & 11.45 & 9.71 \\
Glycine & 7.23 & 8.20 \\
Histidine & 2.10 & 1.78 \\
Isoleucine & 5.20 & 5.74 \\
Leucine & 8.55 & 8.86 \\
Lysine & 7.45 & 4.49 \\
Methionine & 1.39 & 2.28 \\
Phenylalanine & 4.06 & 4.56 \\
Proline & 4.21 & 5.94 \\
Serine & 7.11 & 4.56 \\
Threonine & 6.60 & 5.74 \\
Tryptophan & & 2.68 \\
Tyrosine & 3.29 & 1.51 \\
Valine & 6.77 & 7.01 \\
\hline Total & 100.0 & 100.0 \\
\hline
\end{tabular}

\subsection{Expression and Purification of Recombinant IgG}

Recombinant human IgG1 directed against bovine serum albumin [23] was produced in silkworms using rBmNPV bacmid systems using protocols described previously [14,18,19,24]. Fifth-instar hybrid Kinsyu $\times$ Syowa silkworm larvae (Funakoshi Co., Ltd. Tokyo, Japan) were fed on an artificial diet every $12 \mathrm{~h}$, and were kept at $27^{\circ} \mathrm{C}$ with a $12 \mathrm{~h} / 12 \mathrm{~h}$ light/dark cycle. To produce recombinant IgG1, genes for the heavy and light chains were cloned into a cysteine protease-deficient and chitinase-deficient B. mori nucleopolyhedrovirus (BmNPV-CP--Chi-) bacmid, yielding a recombinant virus (BmNPV bacmid/29IJ6 IgG) used to infect silkworms. With proper feeding, the fifth-instar larvae pupated typically nine days later, which were subsequently incubated at $27^{\circ} \mathrm{C}$ in dark for another nine 
days. To express recombinant IgG1, BmNPV bacmid/29IJ6 IgG was injected into nine-day-old pupae or two-day-old fifth instar larvae, together with 1,2-dimyristyloxypropyl-3-dimethyl-hydroxyethyl ammonium bromide (DMRIE-C, Life Technologies Japan, Tokyo, Japan). Bacmid-injected larvae and pupae were maintained at $27^{\circ} \mathrm{C}$ for 6 and 7 days, respectively, for protein expression. Timeline and procedure of the protein expression in silkworm pupae are summarized in Figure 1.

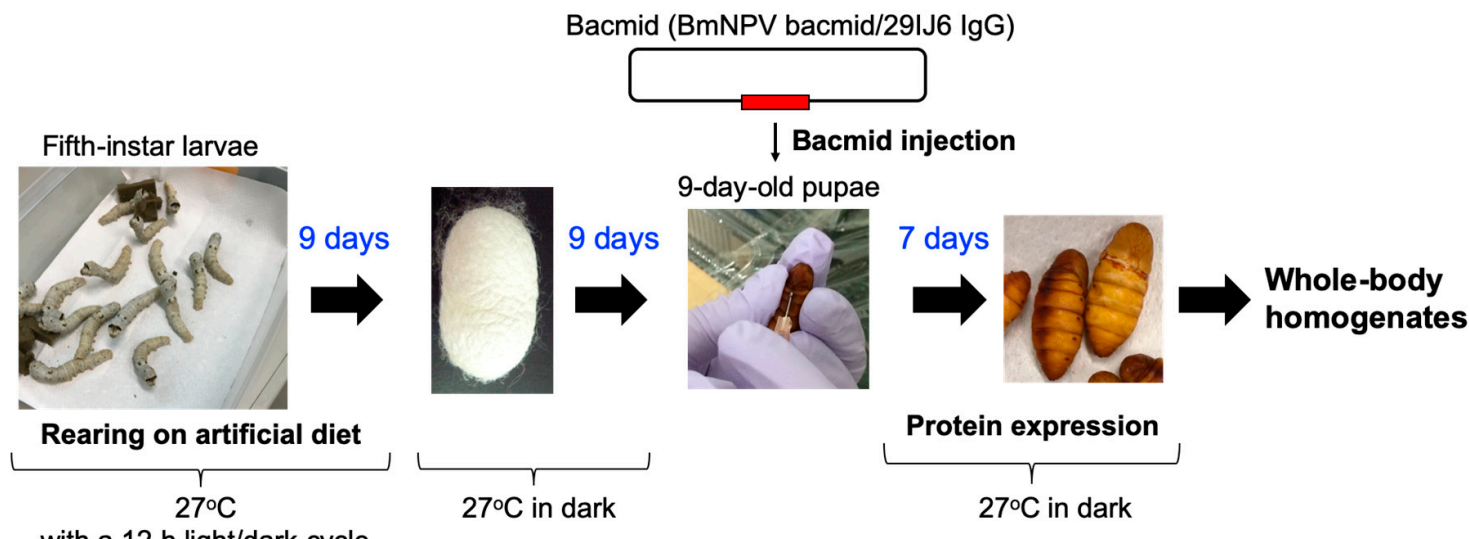

with a $12 \mathrm{~h}$ light/dark cycle

Figure 1. Timeline and procedure of the protein expression in silkworm pupae.

Purification of IgG was performed as previously described [14,18]. The bacmid-injected pupae were homogenized with Tris-buffered saline containing Tween-20, and were then centrifuged $(20,000 \times g, 40 \mathrm{~min})$ after which the sediments were removed. From the bacmid-injected larvae, the hemolymph was collected and centrifuged $(19,000 \times g$ for $30 \mathrm{~min})$. The supernatant was filtered using a $0.45-\mu \mathrm{m}$ nitrocellulose membrane filter (Merck Millipore, Burlington, MA, USA) and then loaded onto an Affi-Gel protein A column (GE Healthcare Life-Sciences, Marlborough, MA, USA). IgG was further purified by gel-filtration chromatography using a Superose 12 column (GE Healthcare Life-Sciences, Marlborough, MA, USA).

Chinese hamster ovary $(\mathrm{CHO})$ cell line producing rituximab, anti-CD20 mouse-human chimeric IgG1, was prepared in-house. Briefly, heavy-chain and light-chain genes of rituximab were ligated into the Mammalian PowerExpress system ${ }^{\circledR}$ vector (Toyobo, Otsu, Japan). Suspension-adapted CHO-K1 cells (ATCC CRL-9618) were transfected with the vector and the stable cell lines were established by single colony picking. Isotope labeling of rituximab was made as described previously with slight modifications [12,13]. For methionine-specific ${ }^{13} \mathrm{C}$ labeling, the $\mathrm{CHO}$ cell line was cultivated with a modified Nissui NYSF 404 medium (supplemented with $2 \%$ dialyzed fetal bovine serum and $7.5 \mu \mathrm{g} / \mathrm{mL}$ puromycin) in which L-methionine was replaced by [methyl $\left.{ }^{13} \mathrm{C}\right]$ methionine. Following the growth of these cells, IgG proteins were purified from the supernatant of the medium using protein A affinity chromatography and gel filtration as described above. In this study, $2.5 \mathrm{mg}$ of recombinant IgG glycoprotein was subjected to NMR measurements, which was produced with 7 pupae fed with $82 \mathrm{~g}$ of artificial diet containing $200 \mathrm{mg}$ of [methyl- ${ }^{13} \mathrm{C}$ ]methionine.

\subsection{Limited Proteolysis of IgG}

The Fab and Fc fragments of IgG were prepared as previously described [25,26]. IgG was cleaved by papain digestion, performed at $37^{\circ} \mathrm{C}$ for $12 \mathrm{~h}$ in $75 \mathrm{mM}$ sodium phosphate buffer [pH 7.0, containing $75 \mathrm{mM} \mathrm{NaCl}$ and $2 \mathrm{mM}$ ethylenediaminetetraacetic acid (EDTA)]. The IgG concentration was $10 \mathrm{mg} / \mathrm{mL}$ and the papain: IgG ratio was 1:50 (w/w). The digestion products were loaded onto an Affi-Gel protein A column. Fc and Fab fragments were then collected from the bound and unbound fractions, respectively. Both fragments were further purified by a Superose 12 gel-filtration column. Purity of each of the protein preparations was checked by sodium dodecyl sulfate-polyacrylamide gel electrophoresis (SDS-PAGE). 


\subsection{Mass Spectrometric Measurement of Stable-Isotope Enrichment}

Prior to amino-acid analysis, samples of isotope-labeled artificial diet, crude protein extract, and IgG purified from silkworm pupae were hydrolyzed by $\mathrm{HCl}$ for $24 \mathrm{~h}$ at $110{ }^{\circ} \mathrm{C}$. After cooling to room temperature, the hydrolyzate was filtered through a polytetraflouroethylene (PTFE) membrane filter $(0.45-\mu \mathrm{m}$ pore size, Millipore, Burlington, MA, USA). The solution was transferred into an eggplant-shaped flask, and unreacted $\mathrm{HCl}$ was removed by evaporation under a vacuum at $40{ }^{\circ} \mathrm{C}$. The dried residue was dissolved in Milli-Q water. Liquid chromatography-mass spectrometry (LC-MS) system used in this study was composed of an ACQUITY UPLC (Waters Corporation, Milford, MA, USA) coupled to a Xevo G2-XS QTOF mass spectrometer (Waters Corporation) with a heated electrospray ionization (ESI) source. Amino acids were separated on a Discovery HSF5 column (Merck, Kenilworth, NJ, USA) with dimensions of 2.1 i.d. $\times 150 \mathrm{~mm}$ and a particle size of 3- $\mu \mathrm{m}$. A set of mobile phases was used: $0.1 \%(v / v)$ formic acid $(\mathrm{A})$ and $0.1 \%(v / v)$ formic acid in acetonitrile (B). The gradient conditions were as follows: $t=0-5 \mathrm{~min}, 0 \% \mathrm{~B}, t=5-15 \mathrm{~min}, 0-40 \% \mathrm{~B}, t=15-16 \mathrm{~min}$, $40-100 \% \mathrm{~B}, t=16-20 \mathrm{~min}, 100 \% \mathrm{~B}, t=20-20.1 \mathrm{~min}, 100-0 \% \mathrm{~B}, t=20.1-25 \mathrm{~min}, 0 \% \mathrm{~B}$. The flow rate was set at $0.25 \mathrm{~mL} / \mathrm{min}$ and the column oven temperature was $45^{\circ} \mathrm{C}$. The injection volume was $1 \mu \mathrm{L}$. The ESI-MS conditions were as follows: Source Temperature, $120^{\circ} \mathrm{C}$, Desolvation Temperature, $450{ }^{\circ} \mathrm{C}$, Desolvation Gas Flow, 800 L/h, Cone Gas Flow, 50 L/h, and capillary voltage, $1.5 \mathrm{kV}$ for positive mode.

\subsection{Glycosylation Profiling}

$N$-glycosylation profiling of IgG was performed based on the high-performance liquid chromatography (HPLC) mapping technique described previously [27]. Isotope-labeled IgG-Fc glycoprotein $(0.2 \mathrm{mg})$ was used as a starting material. N-glycans of the pupa-derived IgG glycoprotein were released by hydrazinolysis [28,29], tagged with 2-aminopyridine, and loaded onto an amide column (Tosoh Co., Tokyo, Japan). Next, each fraction separated on the amide column was subjected to an octadecylsilyl ODS column (Shimadzu Co., Kyoto, Japan). The elution time on each HPLC column was expressed in the glucose units (G.U.), in reference to the pyridylamino (PA) derivatized isomalto-oligosaccharide mixture. Structural identification was based on the elution position on the HPLC column in the GALAXY database (http://www.glycoanalysis.info) [27].

\subsection{NMR Measurements}

For NMR measurements, Fab/Fc fragments and full-length IgG glycoproteins were dissolved in $0.5 \mathrm{~mL}$ of $5 \mathrm{mM}$ sodium phosphate buffer [pH 6.0, containing $50 \mathrm{mM} \mathrm{NaCl}$ and $10 \%(v / v) \mathrm{D}_{2} \mathrm{O}$ ] at a protein concentration of $10 \mathrm{mg} / \mathrm{mL}$. Two-dimensional methyl-transverse relaxation optimized spectroscopy(TROSY) spectral data were acquired at $37^{\circ} \mathrm{C}$ using an AVANCE 800 spectrometer equipped with a cryogenic probe (Bruker BioSpin, Fällanden, Switzerland). Assignments for the methionyl methyl resonances of Fc were made based on the previously reported backbone assignments [30] by analyzing nuclear Overhauser effect (NOE) connectivities observed using AVANCE 800 and AVANCEIII 900 spectrometers equipped with cryogenic probes (Bruker BioSpin, Fällanden, Switzerland). Chemical shifts of ${ }^{1} \mathrm{H}$ were referenced to 4,4-dimethyl-4-silapentane-1-sulfonic acid ( $\left.0 \mathrm{ppm}\right)$, and ${ }^{13} \mathrm{C}$ chemical shifts were referenced indirectly using the gyromagnetic ratios of ${ }^{13} \mathrm{C}$ and ${ }^{1} \mathrm{H}\left(\gamma^{13} \mathrm{C} / \gamma^{1} \mathrm{H}=0.25144952\right)$. All NMR data were processed using NMR Pipe [31] and were analyzed using CCPNMR [32].

\section{Results and Discussion}

\subsection{Optimization of Artificial Diet Composition}

In our previous study, ${ }^{15} \mathrm{~N}$-labeled IgG was produced by silkworm larvae fed the artificial diet A40M10 in which amino acids were supplied as yeast crude protein extract [14]. However, the larvae fed this artificial diet did not grow enough to pupate. In addition, amino-acid selective labeling is difficult in this protocol. To solve these problems, we adopted the A30M10 and A20M20 artificial diets in which the yeast extract was replaced by an amino-acid mixture. These recipes allowed 
the larvae to grow into pupae at day 9 (Figure 2). Comparison of the two growth curves indicate that a higher amount of mulberry powder enhances larval appetite and growth. Hence, we used A20M20 for expression of recombinant IgG.

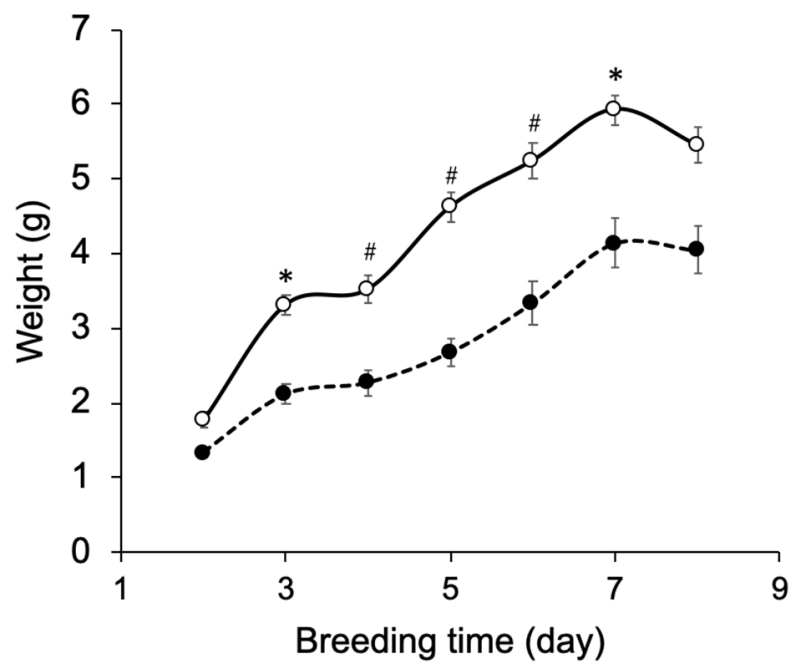

Figure 2. Growth curve of silkworm larvae reared on artificial diets. Silkworm larvae $(n=10)$ were reared on the artificial diets A20M20 (open circle) and A30M10 (closed circle) from the fifth-instar larval stage. Mean \pm s.e.m. values are shown, ${ }^{*} p<0.001$ and ${ }^{*} p<0.0001$ by Student's $t$-test.

\subsection{Production of IgG in Silkworm Pupae}

IgG production yields were compared between larvae and pupae from identical A20M20-fed rearing environments. The only difference between treatments was the time point of bacmid injection, i.e., 2-day-old fifth instar larvae and 9-day-old pupae. Larval growth significantly slowed after bacmid injection (Figure S1). Recombinant IgG yields purified from the hemolymph fluids of larvae and whole-body homogenates of pupae were $0.07 \mathrm{mg} / \mathrm{larva}$ and $0.35 \mathrm{mg} / \mathrm{pupa}$, respectively. Thus, pupae extracts showed a five-fold greater yield than larval extracts.

BmNPV infects blood cells and fat body cells in silkworms. Pupal body tissues primarily consist of fat body cells, which can express recombinant proteins. For this reason, recombinant IgG can be harvested from pupal whole-body homogenates. In contrast, because the larval midgut contains a large amount of proteases, it is necessary to extract body fluid prior to recombinant protein purification [33-35]. It is possible that this is the reason for the higher recombinant IgG yield of pupae relative to larvae. There have been several reports of glycoprotein production in silkworm pupae including porcine lactoferrin (0.2 mg/pupa) [36] and human granulocyte macrophage colony stimulating factor $(0.1 \mathrm{mg} / \mathrm{pupa})$ [37], suggesting that our method can be applicable for isotope-labeling of other proteins in high yields.

Recombinant IgG purified from pupae was subjected to HPLC-based glycosylation profiling (Figure S2 and Table 3). The N-glycans mainly consisted of three kinds of pauci-mannose-type oligosaccharides [Man $\alpha 1-6$ Man $\beta 1-4 G l c N A c \beta 1-4(F u c \alpha 1-6) G l c N A c, \quad M a n \alpha 1-6(M a n \alpha 1-3) M a n \beta 1-$ 4GlcNAc $\beta 1-4$ (Fuc $\alpha 1-6)$ GlcNAc, and Man $\alpha 1-6($ GlcNAc $\beta 1-2 M a n \alpha 1-3) M a n \beta 1-4 G l c N A c \beta 1-4(F u c \alpha 1-$ 6)GlcNAc]. These results are consistent with those of previous reports [18,24], confirming that the pupa-derived IgG retained the nonreducing terminal GlcNAc $\beta 1-2$ moiety, unlike the larva-derived IgG. This difference may be due to reduced $\beta-N$-acetylhexosaminidase activity in pupae. 
Table 3. N-glycosylation profile of IgG expressed by silkworm pupae reared on artificial diet A20M20.

\begin{tabular}{|c|c|c|c|}
\hline $\begin{array}{l}\text { G.U. } \\
\text { (ODS) }\end{array}$ & $\begin{array}{c}\text { G.U. } \\
\text { (Amide) }\end{array}$ & $\begin{array}{c}\text { Relative } \\
\text { Quantity (\%) }\end{array}$ & Structure \\
\hline 10.4 & 3.5 & 36.1 & 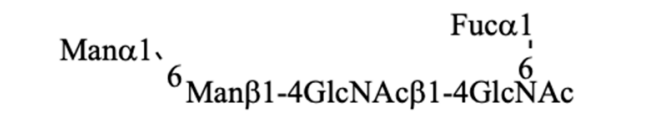 \\
\hline 10.3 & 4.8 & 41.1 & 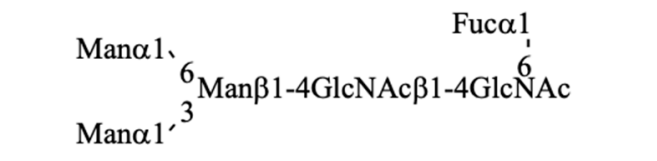 \\
\hline 10.3 & 5.2 & 16.6 & 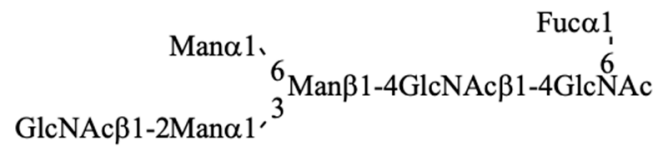 \\
\hline & & 6.2 & others \\
\hline
\end{tabular}

\subsection{Characterization of ${ }^{13} \mathrm{C}$-Labeled $\operatorname{Ig} G$}

Using the A20M20 diet containing [methyl $-{ }^{13} \mathrm{C}$ ]methionine, we performed metabolic ${ }^{13} \mathrm{C}$ labeling of the recombinant IgG glycoprotein produced by pupae (Figure 3). LC-MS analyses revealed that ${ }^{13} \mathrm{C}$ enrichment degrees of methionine were $99 \%$ in the A20M20 diet used for rearing and approximately $80 \%$ in the crude protein fractions and recombinant IgG harvested from the pupae (Figure 4). Since we started rearing silkworm larvae with the isotope-labeled artificial diet at their fifth instar stage, the isotope dilution is likely to be ascribed to pre-existing unlabeled amino acids in the silkworm body. An earlier start of rearing with the isotope-labeled diet would improve ${ }^{13} \mathrm{C}$ labeling efficiency but presumably result in a lower production yield. Taking account of such a trade-off, we suppose that an $80 \%$ enrichment is a good compromise for measuring heteronuclear NMR spectra. Our protocol enabled selective observation of NMR signals originating from IgG methionyl methyl groups (Figure 5).

(A)

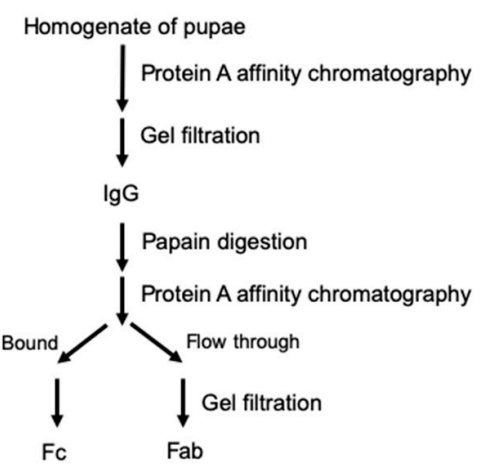

(B)

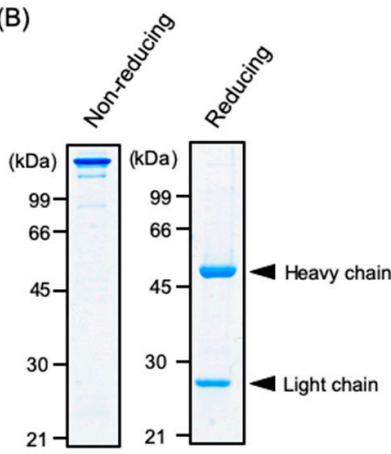

(C)

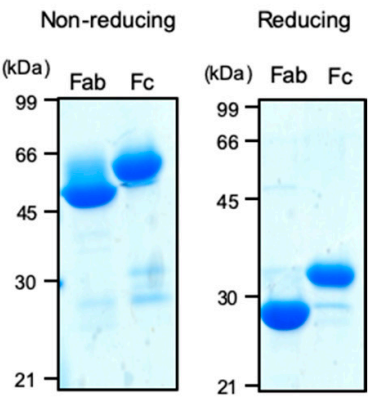

Figure 3. Preparation of $\operatorname{IgG}$ and its proteolytic fragments from silkworm pupae. (A) Scheme for purification and limited proteolysis of IgG. SDS-PAGE profiles of (B) IgG and (C) its Fab and Fc fragments from the pupae under non-reducing and reducing conditions. Arrowheads indicate the positions of heavy or light chains. 


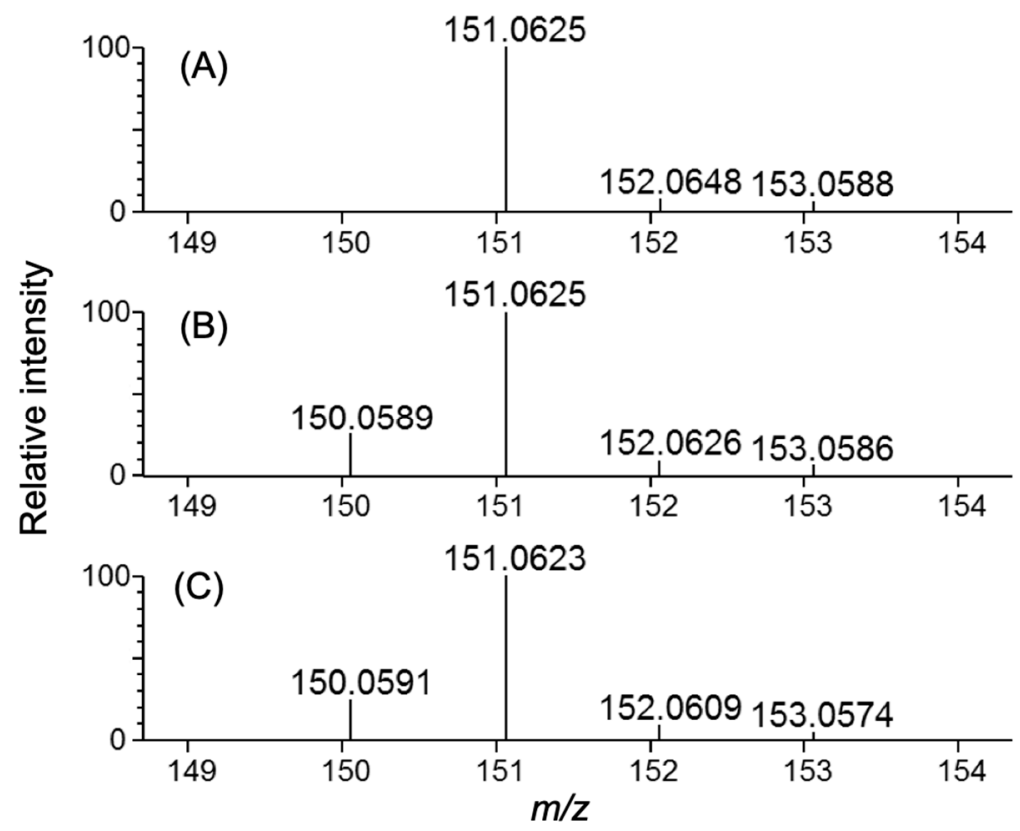

Figure 4. Methionine LC-MS spectra of isotopically labeled samples. Samples shown are: (A) artificial diet A20M20 containing [methyl- ${ }^{13} \mathrm{C}$ ]methionine used for metabolic labeling, (B) homogenate, and $(\mathrm{C})$ purified IgG originating from silkworm pupae reared on the ${ }^{13} \mathrm{C}$-labeled artificial diet.

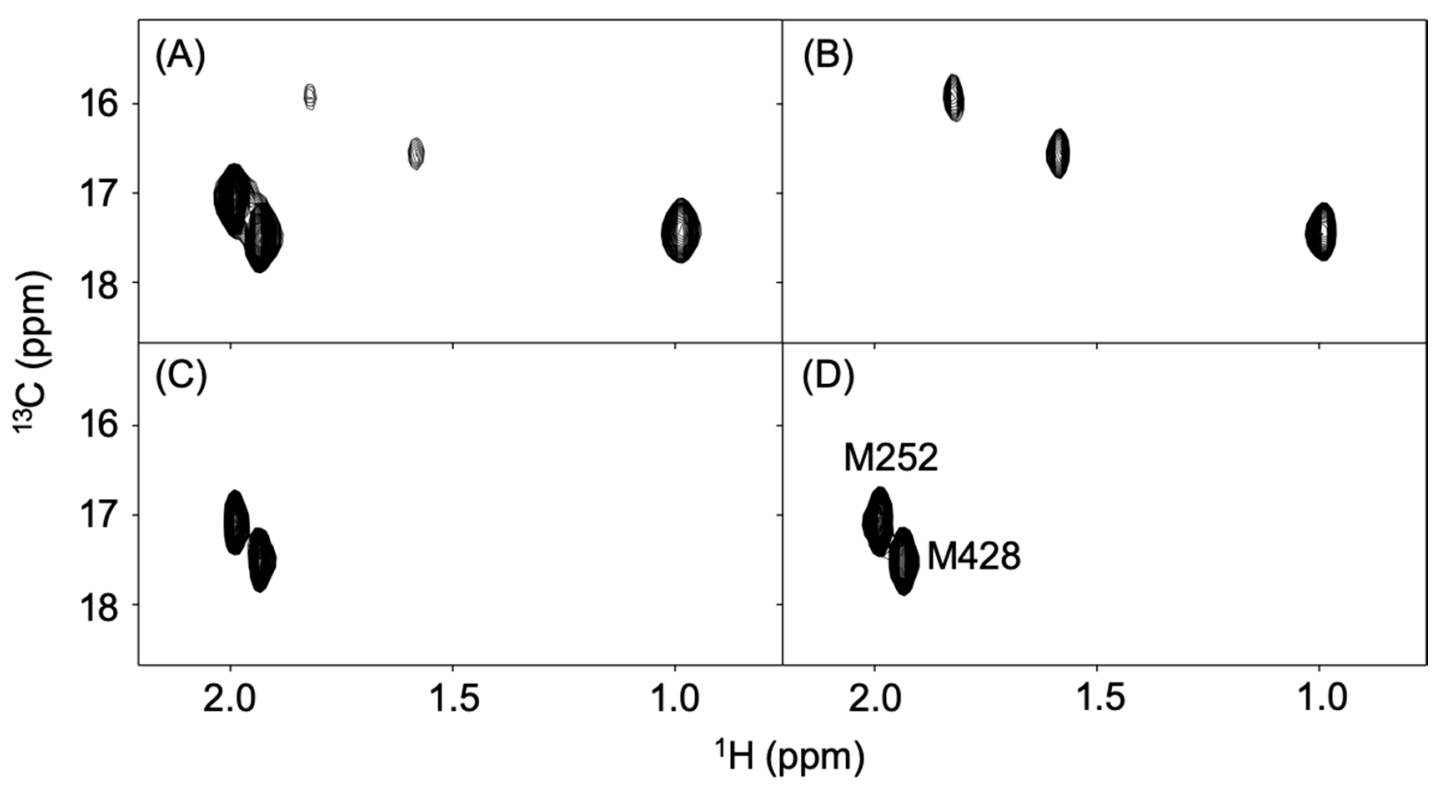

Figure 5. Methyl-TROSY spectra of recombinant $\operatorname{IgG}$ and its proteolytic fragments labeled with ${ }^{13} \mathrm{C}$ at the methionyl methyl groups. (A) full-length $\mathrm{IgG}$ produced in silkworm pupae, (B) Fab, and (C) Fc fragments of pupae-expressed IgG and (D) Fc fragment of CHO-expressed IgG.

The recombinant IgG contains three and two methionine residues in the Fab and Fc regions, respectively [23]. This was confirmed by spectral data for the Fab and Fc fragments, which exhibited additivity so as to reproduce the full-length IgG spectrum (Figure 5B,C). Furthermore, the Fc spectrum was compared with that of an authentic human IgG1-Fc preparation produced in CHO cells, thereby confirming the conformational integrity of the Fc region (Figure 5C,D).

These data indicate that silkworm pupae are capable of producing stable-isotope labeled recombinant IgG in much higher yields than larvae. We have previously demonstrated that antibody production yield in silkworm can be improved by a factor 5 upon co-expression with molecular 
chaperones [18]. When compared with the mammalian expression systems taking this into account, the cost for producing the isotope-labeled IgG glycoproteins are comparable in silkworm pupae, which, however, do not require any expensive equipment such as the $\mathrm{CO}_{2}$ incubator. Therefore, the total cost will be less expensive in the silkworm-based method, which also does not take up much space, enabling production of different proteins with different labeling modes in parallel. In terms of the time period for obtaining the products, both the mammalian and pupa systems require approximately three to four weeks from the start of culture with isotope-labelled metabolic precursors to harvest. However, it generally takes a couple of months to establish a mammalian cell line that can produce a recombinant antibody at a high expression level. Thus, the pupa expression system is excellent in terms of flexibility and efficiency in contrast to large-scale culture of mammalian cells.

\section{Conclusions}

In this study, we demonstrate the utility of silkworm pupae as factories for producing isotope-labeled recombinant glycoproteins. This is a significant improvement over previous work using silkworm larvae since pupae are easier to handle and store and show an increased IgG yield. Moreover, the protocol developed here enables amino-acid selective labeling of glycoproteins, which complements the non-selective labeling technique we established previously [14]. Efficiency of amino-acid selective labeling depends on metabolic pathways. In silkworm, essential amino acids are arginine, histidine, isoleucine, leucine, lysine, methionine, phenylalanine, threonine, tryptophan, and valine, while aspartic and glutamic acids are interconverted by transaminases in larval tissues [38]. These have to be taken into account in order to improve labeling efficiency.

Recombinant IgG glycoproteins are currently used as biopharmaceuticals [39,40]. NMR is expected to offer a useful tool for assessing conformational integrity of therapeutic antibodies. In particular, NMR signals originating from methyl groups can be useful spectroscopic probes for monitoring local conformations in larger glycoproteins, such as IgG [41,42]. Our pupa-based protocol can be useful for preparing a series of glycoprotein samples in which different amino-acid residues are selectively labeled because it can save time, space, and effort relative to those using larvae or other eukaryotic expression vehicles. Several attempts have been made not only for increasing yields of recombinant glycoproteins produced by silkworms, e.g., by co-expression with molecular chaperones [18] but also to engineer their glycoforms, e.g., by co-expression with human glycosyltransferases [24]. Our pupae-based approach combined with these techniques opens the possibility of recombinant glycoproteins with functional modifications.

Supplementary Materials: The following are available online at http://www.mdpi.com/2218-273X/10/11/1482/s1. Figure S1: Effects of bacmid injection on silkworm larvae growth. Growth curve of silkworm larvae $(n=6)$ reared on artificial diet A20M20 with (closed circle) or without (open circle) bacmid injection on the second day. Means \pm s.e.m. values are shown. ${ }^{*} p<0.0005$ by Student's $t$-test. Figure S2: $N$-glycosylation profile of IgG expressed by silkworm pupae reared on artificial diet A20M20. Key symbols: Fuc (triangle), GlcNAc (square), Man (circle). Asterisk represents a contaminating signal.

Author Contributions: Conceptualization, H.Y., J.Y., and K.K. Methodology, J.Y., T.K., and E.P. Validation, H.Y., S.Y., R.Y., A.I., and T.Y. Investigation, H.Y., S.Y., R.Y., and A.I. Resources, M.O., T.K., E.Y.P. Data Curation, H.Y., S.Y., and R.Y. Writing-Original Draft Preparation, H.Y. and S.Y. Writing-Review \& Editing, K.K. Visualization, H.Y. and S.Y. Supervision, K.K. Project Administration, K.K. Funding Acquisition, S.Y., R.Y., and K.K. All authors have read and agreed to the published version of the manuscript.

Funding: This work was supported in part by the JSPS Research Fellowship for Young Scientists (to R.Y.) and the Grants-in-Aid for Scientific Research (Grant Numbers, JP18K14892 and JP20K15981 to S.Y., JP19H01017 to K.K., and JP19J15602 to R.Y.) from the Ministry of Education, Culture, Sports, Science and Technology (MEXT), Japan. This study was also supported by the Nanotechnology Platform Program (Molecule and Material Synthesis) of MEXT, Advanced NMR Application and Platform (program No. PF17-01-R-008 and PF19-01-R-022), and by Joint Research of the Exploratory Research Center on Life and Living Systems (ExCELLS) (ExCELLS program No.20-308 to H.Y.). 
Acknowledgments: We thank Kiyomi Senda and Kumiko Hattori (Nagoya City University) for their help in purification of IgG.

Conflicts of Interest: The authors declare no conflict of interest.

\section{References}

1. Wingfield, P.T. Overview of the purification of recombinant proteins. Curr. Protoc. Protein Sci. 2015, 6, 1-6. [CrossRef]

2. Adrio, J.L.; Demain, A.L. Recombinant organisms for production of industrial products. Bioeng. Bugs 2010, 1, 116-131. [CrossRef]

3. Baneyx, F. Recombinant protein expression in Escherichia coli. Curr. Opin. Biotechnol. 1999, 10, 411-421. [CrossRef]

4. Rosano, G.L.; Ceccarelli, E.A. Recombinant protein expression in Escherichia coli: Advances and challenges. Front. Microbiol. 2014, 5, 172. [CrossRef]

5. Dutta, A.; Saxena, K.; Schwalbe, H.; Klein-Seetharaman, J. Isotope labeling in mammalian cells. Methods Mol. Biol. 2012, 831, 55-69. [CrossRef]

6. Ohki, S.; Dohi, K.; Tamai, A.; Takeuchi, M.; Mori, M. Stable-isotope labeling using an inducible viral infection system in suspension-cultured plant cells. J. Biomol. NMR 2008, 42, 271-277. [CrossRef]

7. Saxena, K.; Dutta, A.; Klein-Seetharaman, J.; Schwalbe, H. Isotope labeling in insect cells. Methods Mol. Biol. 2012, 831, 37-54. [CrossRef]

8. Takahashi, H.; Shimada, I. Production of isotopically labeled heterologous proteins in non-E. coli prokaryotic and eukaryotic cells. J. Biomol. NMR 2010, 46, 3-10. [CrossRef]

9. Skrisovska, L.; Schubert, M.; Allain, F.H.T. Recent advances in segmental isotope labeling of proteins: NMR applications to large proteins and glycoproteins. J. Biomol. NMR 2010, 46, 51-65. [CrossRef] [PubMed]

10. Skora, L.; Shrestha, B.; Gossert, A.D. Isotope Labeling of Proteins in Insect Cells. In Methods in Enzymology; Academic Press Inc.: Cambridge, MA, USA, 2015; Volume 565, pp. 245-288.

11. Franke, B.; Opitz, C.; Isogai, S.; Grahl, A.; Delgado, L.; Gossert, A.D.; Grzesiek, S. Production of isotope-labeled proteins in insect cells for NMR. J. Biomol. NMR 2018, 71, 173-184. [CrossRef]

12. Yamaguchi, Y.; Kato, K. Dynamics and interactions of glycoconjugates probed by stable-isotope-assisted NMR spectroscopy. Methods Enzymol. 2010, 478, 305-322. [CrossRef]

13. Yamaguchi, Y.; Yagi, H.; Kato, K. Stable Isotope Labeling of Glycoproteins for NMR Study. In New Developments in NMR; Royal Society of Chemistry: Cambridge, UK, 2017; pp. 194-207. ISBN 9781782621331.

14. Yagi, H.; Nakamura, M.; Yokoyama, J.; Zhang, Y.; Yamaguchi, T.; Kondo, S.; Kobayashi, J.; Kato, T.; Park, E.Y.; Nakazawa, S.; et al. Stable isotope labeling of glycoprotein expressed in silkworms using immunoglobulin $\mathrm{G}$ as a test molecule. J. Biomol. NMR 2015, 62, 157-167. [CrossRef]

15. Yagi, H.; Fukuzawa, N.; Tasaka, Y.; Matsuo, K.; Zhang, Y.; Yamaguchi, T.; Kondo, S.; Nakazawa, S.; Hashii, N.; Kawasaki, N.; et al. NMR-based structural validation of therapeutic antibody produced in Nicotiana benthamiana. Plant Cell Rep. 2015, 34, 959-968. [CrossRef]

16. Brinson, R.G.; Marino, J.P.; Delaglio, F.; Arbogast, L.W.; Evans, R.M.; Kearsley, A.; Gingras, G.; Ghasriani, H.; Aubin, Y.; Pierens, G.K.; et al. Enabling adoption of 2D-NMR for the higher order structure assessment of monoclonal antibody therapeutics. MAbs 2019, 11, 94-105. [CrossRef]

17. Kato, T.; Kajikawa, M.; Maenaka, K.; Park, E.Y. Silkworm expression system as a platform technology in life science. Appl. Microbiol. Biotechnol. 2010, 85, 459-470. [CrossRef]

18. Dojima, T.; Nishina, T.; Kato, T.; Uno, T.; Yagi, H.; Kato, K.; Ueda, H.; Park, E.Y. Improved secretion of molecular chaperone-assisted human IgG in silkworm, and no alterations in their $N$-linked glycan structures. Biotechnol. Prog. 2010, 26, 232-238. [CrossRef]

19. Park, E.Y.; Ishikiriyama, M.; Nishina, T.; Kato, T.; Yagi, H.; Kato, K.; Ueda, H. Human IgG1 expression in silkworm larval hemolymph using BmNPV bacmids and its $N$-linked glycan structure. J. Biotechnol. 2009, 139, 108-114. [CrossRef]

20. Ito, T.; Arai, N. An amino-acid diet for the silkworm, Bombyx mori L. Nippon Nōgeikagaku Kaishi 1966, 40, 110-112. [CrossRef]

21. Horie, Y.; Watanabe, K.; Ito, T. Further studies on the requirements for B vitamins. Bull. Seric. Exp. Sta. 1966, 20, 393-409. 
22. Hirayama, C.; Konno, K.; Shinbo, H. Utilization of ammonia as a nitrogen source in the silkworm, Bombyx mori. J. Insect Physiol. 1996, 42, 982-988. [CrossRef]

23. Aburatani, T.; Ueda, H.; Nagamune, $T$. Importance of a CDR $\mathrm{H} 3$ basal residue in $\mathrm{V}_{\mathrm{H}} / \mathrm{V}_{\mathrm{L}}$ interaction of human antibodies. J. Biochem. 2002, 132, 775-782. [CrossRef] [PubMed]

24. Kato, T.; Kako, N.; Kikuta, K.; Miyazaki, T.; Kondo, S.; Yagi, H.; Kato, K.; Park, E.Y. N-Glycan Modification of a recombinant protein via coexpression of human glycosyltransferases in silkworm pupae. Sci. Rep. 2017, 7, 1-10. [CrossRef]

25. Yamaguchi, Y.; Nishimura, M.; Nagano, M.; Yagi, H.; Sasakawa, H.; Uchida, K.; Shitara, K.; Kato, K. Glycoform-dependent conformational alteration of the Fc region of human immunoglobulin G1 as revealed by NMR spectroscopy. Biochim. Biophys. Acta 2006, 1760, 693-700. [CrossRef]

26. Yamaguchi, Y.; Kim, H.H.; Kato, K.; Masuda, K.; Shimada, I.; Arata, Y. Proteolytic fragmentation with high specificity of mouse immunoglobulin $\mathrm{G}$ mapping of proteolytic cleavage sites in the hinge region. J. Immunol. Methods 1995, 181, 259-267. [CrossRef]

27. Takahashi, N.; Kato, K. GALAXY(Glycoanalysis by the three axes of MS and chromatography): A web application that assists structural analyses of N-glycans. Trends Glycosci. Glycotechnol. 2003, 15, 235-251. [CrossRef]

28. Takasaki, S.; Mizuochi, T.; Kobata, A. Hydrazinolysis of asparagine-linked sugar chains to produce free oligosaccharides. Methods Enzymol. 1982, 83, 263-268.

29. Yosizawa, Z.; Sato, T.; Schmid, K. Hydrazinolysis of $\alpha 1$-acid glycoprotein. Biochim. Biophy. Acta-Gen. Subj. 1966, 121, 417-420. [CrossRef]

30. Yagi, H.; Zhang, Y.; Yagi-Utsumi, M.; Yamaguchi, T.; Iida, S.; Yamaguchi, Y.; Kato, K. Backbone 1H, $13 \mathrm{C}$, and $15 \mathrm{~N}$ resonance assignments of the $\mathrm{Fc}_{\mathrm{C}}$ fragment of human immunoglobulin G glycoprotein. Biomol. NMR Assign. 2015, 9, 257-260. [CrossRef]

31. Delaglio, F.; Grzesiek, S.; Vuister, G.W.; Zhu, G.; Pfeifer, J.; Bax, A. NMRPipe: A multidimensional spectral processing system based on UNIX pipes. J. Biomol. NMR 1995, 6, 277-293. [CrossRef]

32. Vranken, W.F.; Boucher, W.; Stevens, T.J.; Fogh, R.H.; Pajon, A.; Llinas, M.; Ulrich, E.L.; Markley, J.L.; Ionides, J.; Laue, E.D. The CCPN data model for NMR spectroscopy: Development of a software pipeline. Proteins Struct. Funct. Genet. 2005, 59, 687-696. [CrossRef]

33. Xu, P.; Zhang, M.; Qian, P.; Li, J.; Wang, X.; Wu, Y. ITRAQ-based quantitative proteomic analysis of digestive juice across the first $48 \mathrm{~h}$ of the fifth instar in silkworm larvae. Int. J. Mol. Sci. 2019, 20, 6113. [CrossRef] [PubMed]

34. Holtof, M.; Lenaerts, C.; Cullen, D.; Vanden Broeck, J. Extracellular nutrient digestion and absorption in the insect gut. Cell Tissue Res. 2019, 377, 397-414. [CrossRef] [PubMed]

35. Franzetti, E.; Huang, Z.J.; Shi, Y.X.; Xie, K.; Deng, X.J.; Li, J.P.; Li, Q.R.; Yang, W.Y.; Zeng, W.N.; Casartelli, M.; et al. Autophagy precedes apoptosis during the remodeling of silkworm larval midgut. Apoptosis 2012, 17, 305-324. [CrossRef]

36. Wang, Y.; Wu, X.; Liu, G.; Cao, C.; Huang, H.; Xu, Z.; Liu, J. Expression of porcine lactoferrin by using recombinant baculovirus in silkworm, Bombyx mori L., and its purification and characterization. Appl. Microbiol. Biotechnol. 2005, 69, 385-389. [CrossRef] [PubMed]

37. Chen, J.; Wu, X.F.; Zhang, Y.Z. Expression, purification and characterization of human GM-CSF using silkworm pupae (Bombyx mori) as a bioreactor. J. Biotechnol. 2006, 123, 236-247. [CrossRef] [PubMed]

38. Bheemeswar, B.; Faulkner, P. Metabolism of oximes in the silkworm Bombyx mori L.-I Inhibition of transaminases. J. Insect Physiol. 1959, 3, 349-356. [CrossRef]

39. Kaplon, H.; Muralidharan, M.; Schneider, Z.; Reichert, J.M. Antibodies to watch in 2020. MAbs 2020, $12,1703531$. [CrossRef] [PubMed]

40. Kesik-Brodacka, M. Progress in biopharmaceutical development. Biotechnol. Appl. Biochem. 2018, 65, 306-322. [CrossRef] 
41. Yanaka, S.; Yagi, H.; Yogo, R.; Yagi-Utsumi, M.; Kato, K. Stable isotope labeling approaches for NMR characterization of glycoproteins using eukaryotic expression systems. J. Biomol. NMR 2018, 71, 193-202. [CrossRef]

42. Pritišanac, I.; Alderson, T.R.; Güntert, P. Automated assignment of methyl NMR spectra from large proteins. Prog. Nucl. Magn. Reson. Spectrosc. 2020, 118-119, 54-73. [CrossRef]

Publisher's Note: MDPI stays neutral with regard to jurisdictional claims in published maps and institutional affiliations.

(C) 2020 by the authors. Licensee MDPI, Basel, Switzerland. This article is an open access article distributed under the terms and conditions of the Creative Commons Attribution (CC BY) license (http://creativecommons.org/licenses/by/4.0/). 